\title{
Meaningful Work and Work Engagement: The Mediating Role of Perceived Opportunities to Craft and Job Crafting Behavior
}

\author{
Dr. Jessica van Wingerden \\ MBA MCC \\ Schouten Global, Centre of Research, Knowledge and Innovation, The Netherlands \\ Erasmus University Rotterdam, The Netherlands \\ E-mail: Jessica.vwingerden@sn.nl; jessica.vanwingerden@gmail.com \\ Joost van der Stoep \\ MSc \\ VU University Amsterdam, The Netherlands \\ Schouten Global, Centre of Research, Knowledge and Innovation, The Netherlands
}

Prof. Dr. Rob Poell

Tilburg University, The Netherlands

Received: Feb. 4, 2018 Accepted: Feb. 28, 2018 Online published: Mar. 7, 2018

doi:10.5296/ijhrs.v8i2.12635 URL: https://doi.org/10.5296/ijhrs.v8i2.12635

\begin{abstract}
This study examines the impact of meaningful work on employees' level of work engagement as mediated by perceived opportunities to craft and job crafting. Based on the literature on meaningful work and job crafting, we hypothesize that meaningful work has a positive relationship with an employee's level of work engagement in two ways, directly and indirectly via perceived opportunities to craft first and job crafting second (sequential mediation). In order to test the hypothesized relations, we conducted a structural equation modeling on a sample of 1148 employees working in various occupations, organizations, and industries in The Netherlands. The results of this analysis provide support for the
\end{abstract}


hypothesized relations, indicating a strong linkage between meaningful work and work engagement and a partially mediating role for perceived opportunities to craft and job crafting. The main theoretical, practical, and methodological implications of this study are discussed.

Keywords: meaningful work, perceived opportunity to craft, job crafting, work engagement, structural equation modelling, mediation

\section{Introduction}

Meaningful work - defined as work that is experienced as particularly significant and holding positive meaning for an individual (Rosso, Dekas, \& Wrzesniewski, 2010, p95) - is highly valued by contemporary employees (Grant, 2007; Harpaz \& Fu, 2002). Some employees prioritize meaningful work even above salary, job security, career opportunities, or working hours (Cascio, 2003). The experience of meaningful work depends on the personal connection between an employee and his or her work, which motivates an employee to go the extra mile at work (Seibert, Wang, \& Courtright, 2011). Studies have linked meaningful work to, for example, employee well-being (Van Wingerden \& Van der Stoep, 2017), while meaningless work has been linked to, for example, disengagement and estrangement (e.g., Nair \& Vohra, 2009; Shantz, Alfes, \& Truss, 2014). Due to these relations, scholars and practitioners in the field of work and organizational psychology have been highly motivated to better understand the impact of meaningful work within organizations.

Although the relation between meaningful work and work engagement is clear, relatively little is known about the processes through which meaningful work actually affects work engagement. Recently, research has identified the mediating role of strengths use in this relation (Van Wingerden \& Van der Stoep, in press). This implies that the experience of meaningful work may alter the way in which employees think and behave at work. Following this line of reasoning, we present a meaningful work - work engagement model that includes mediating roles of perceived opportunities to craft (thinking) and subsequently job crafting behavior (acting). Using a sample of 1148 employees, we test how meaningful work is related to work engagement directly, and indirectly via perceived opportunities to craft and subsequently via job crafting. In other words, we argue that employees who perceive their work as meaningful perceive more opportunities to craft their job and subsequently do so. In the end this job crafting behavior is positively related to employee levels of work engagement.

\section{Theoretical Background}

\subsection{Meaningful work and Work Engagement}

An employee experiences meaningful work when the work's objectives are aligned with his or her own ideals and principles (Thomas \& Velthouse, 1990). Such an experience thus emerges when an employee's personal beliefs, values and behaviors match the requirements of the job (Chalofsky, 2003; Hackman \& Oldham, 1980). Whether or not employees experience their work as meaningful depends on the subjective assessment of the employee and less on the objective reality (Thomas \& Velthouse, 1990). In other words, employees 
experience meaningful work when they perceive their work as significant and important. Although employees vary in their perceptions of meaningful work because they differ in personality, every employee assesses the meaningfulness of work to some extent (Wrzesniewski, McCauley, Rozin, \& Schwartz, 1997).

The experience of meaningful work by employees has a positive impact on personal and work-related outcomes (Baumeister \& Vohs, 2002; Neck \& Milliman, 1994; Pratt \& Ashforth, 2003). For example, recent research has demonstrated that employees who experience meaningful work are more engaged than employees who do not consider their work as meaningful (May, Gilson, \& Harter, 2004; Van Wingerden \& Van der Stoep, 2017). Schaufeli and Bakker (2004, p. 295), defined work engagement as "the positive, fulfilling and work-related state of mind that is characterized by vigor, dedication, and absorption." Employees who are vigorous experience high levels of energy and are mentally resilient at work. Employees who are dedicated are involved in their job and enthusiastic about it. Employees who are absorbed are concentrated and immersed in their work. Combined, we indeed expect that high levels of meaningful work are related to high levels of vigor, dedication, and absorption; and thus to high levels of work engagement.

Although the relation between meaningful work and work engagement has been demonstrated repeatedly before, less is known about the mechanisms that play a role in this relationship. Recently, Van Wingerden and Van der Stoep (in press) have shed new light on this relationship by highlighting the mediating role of strengths use - that is the active deployment of strengths so an employee performs at his or her personal best (Linley \& Harrington, 2006). Van Wingerden and Van der Stoep demonstrated that meaningful work is related to increased performance via strengths use and work engagement. Besides the increased use of strengths, meaningful work has also been associated with organizational citizenship behaviors, which are behaviors that go beyond the formal requirements of work, like volunteering for non-required tasks (Seibert et al., 2011). Following this reasoning, we expect that the experience of meaningful work affect how employees think and act at work. In this study we take a closer look at the relation between meaningful work and work engagement via perceived opportunities to craft and job crafting behavior.

\subsection{Perceived Opportunities to Craft and Job Crafting}

Job crafting has been a well-known predictor of work engagement (Tims, Bakker, \& Derks, 2012; Van Wingerden, Bakker, \& Derks, 2017). Wrzesniewski and Dutton (2001), defined job crafting as employees' self-initiated changes aimed at aligning their job (and work environments) with their own preferences, motives, and passions (Wrzesniewski \& Dutton, 2001; see also Berg, Dutton, \& Wrzesniewski, 2007). Through job crafting, employees redefine the boundaries of their work in three ways. Task crafting, which refers to changing the physical or temporal boundaries of job tasks, relational crafting, which refers to redefining the interpersonal relationships at work, and cognitive crafting, which refers to reconstructing one's cognitions on the meaning or purpose of the job tasks. In the end, all these crafting activities result in permanent changes in job design (LePine \& Van Dyne, 1998). This is because employees who engage in job crafting proactively establish congruence between their talents, strengths, and interests, and their work environment. By 
doing so, employees may experience their job as challenging, while maintaining their level of enjoyment and vitality. In other words, through job crafting employees may influence their levels of work engagement.

Whether or not employees align their job (and work environments) with their own preferences, motives, and passions, may depend on employees' perceived opportunities to craft (Van Wingerden \& Niks, 2017; Van Wingerden \& Poell, 2017; Wrzesniewski, 2003; Wrzesniewski \& Dutton, 2001). Perceived opportunities to craft can be defined as employees' perceptions regarding their opportunities to proactively optimize their own work environment (Van Wingerden \& Poell, 2017). Different studies have indeed shown that employees who perceive more opportunities to craft are more likely to craft their job (Van Wingerden, Derks, Bakker, \& Dorenbosch, 2013; Van Wingerden \& Poell, 2017). For example, participants of a job crafting intervention who stated that they did not succeed in crafting their job during or after the intervention, indicated that they did not perceive any opportunities to do so. They reported that making changes in their work environment was restricted by management, behavioral patterns on the job, or by the culture within the organization. On the other hand, participants who reported that they successfully crafted their work environments indicated that they experienced the opportunities to do so (Van Wingerden et al., 2013; Van Wingerden $\&$ Poell, 2017). In this way, job crafting is related to the perceived opportunities to craft by an employee.

Furthermore, the employees' perceived opportunities to craft depend on the assessment of work characteristics by the employee (Van Wingerden \& Poell, in press). For example, employees' perceived opportunities to craft may be predicted by job resources like autonomy and feedback. Managers who give their employees autonomy in their job and (positive) feedback on their previous job crafting behavior, may positively affect the employees perceived opportunities to craft (see also Wrzesniewski, 2003). This is in line with the findings of a study by Van Wingerden and Niks (2017), which revealed that an employees' perceived opportunities to craft depend on whether or not the employee experience autonomy and opportunities for professional development in his or her work. This all indicates that the assessment of job characteristics by the employee influence his or her perceived opportunities to craft their work.

Following this reasoning, we expect that doing meaningful work is a job characteristic that affects how employees look at their work and thus may affect their perceived opportunities to craft. Experiencing meaningful work stimulates a sense of involvement in the workplace (Seibert et al., 2011). When employees feel that they perform meaningful work, they feel connected with their work and with the outcomes of their work. This motivates them to behave above and beyond expectations. Due to the fit between work and someone's personal beliefs and values, we expect that employees who experience their work as meaningful are also more receptive for opportunities to influence their work. In other words, the experience of meaningful work changes how employees perceive their work and how they perceive the opportunities to actually craft their work.

Combined, we argue that the experience of meaningful work changes the perception of an employee to craft his or her work. This increment in perceived opportunities to craft, in turn, may influence their actual job crafting behavior, which subsequently alters the levels of work 
engagement. In the end, we present a proposed model (see Figure 1) in which meaningful work affects work engagement in two ways: directly, but also indirectly via a sequential mediation model from meaningful work to perceived opportunities to craft, to job crafting, to work engagement. We compared this proposed model with three alternative models. One of the alternative models was in line with research that considers meaningful work mainly as an outcome instead of as an antecedent of job crafting (e.g. Wrzesniewski 2003). All in all, we present the following hypotheses.

H1: Meaningful work is directly and positively related to work engagement.

H2: Meaningful work is indirectly and positively related to work engagement via perceived opportunities to craft and job crafting behavior.

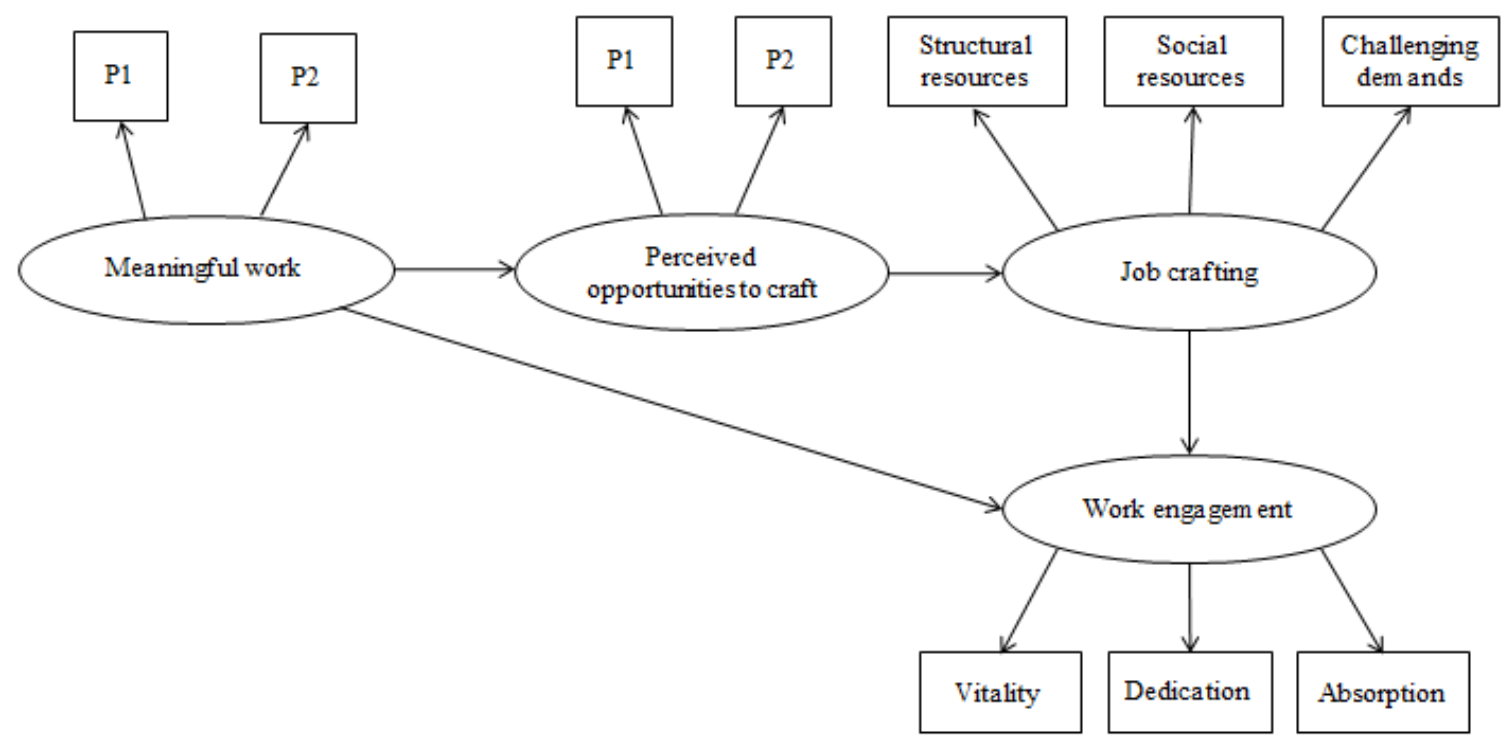

Figure 1. The Proposed Model

\section{Method}

\subsection{Participants and Procedure}

In this quantitative, cross-sectional study we collected data using an online survey, which was announced on a well-known Dutch career development website. In addition, the online link to the survey was shared via various social media channels, such as LinkedIn and Facebook. Data was collected from a diverse population to increase heterogeneity among participants, which facilitates generalization of the research findings (Demerouti \& Rispens, 2014). The online survey was in Dutch and available for two weeks. In total, 1148 employees filled out the survey. A majority of the sample was female (59\%) and most participants (90\%) reported to possess at least a bachelor's degree. Various sectors were represented, with participants working in the public sector (24\%), health care (13\%), professional services (13\%), financial services $(10 \%)$, education $(8 \%)$, industry $(9 \%)$, information technology $(6 \%)$, energy and infrastructure (15\%), and wholesale and retail (7\%). All baseline characteristics of the study population are presented in Table 1. Data was collected in accordance with the ethical guidelines of the Dutch Association of Psychologists and the American Psychological 
Association. In line with the ethical guidelines, participation was completely voluntary, data collection through a self-report survey was exempted from an institutional ethics committee's approval, and the respondents did not receive any compensation for their contribution. Informed consent was given by clicking on the "Finish" button at the end of the survey.

Table 1 . Baseline characteristics of the study population $(n=1148)$

\begin{tabular}{|c|c|c|c|}
\hline Characteristic & $n(\%)$ & Characteristic & $n(\%)$ \\
\hline Sex & & \multicolumn{2}{|l|}{ Supervisory position } \\
\hline Women & $674(59 \%)$ & Yes & $347(30 \%)$ \\
\hline Men & $474(41 \%)$ & No & $801(70 \%)$ \\
\hline Age & & \multicolumn{2}{|l|}{ Self-employed } \\
\hline$<35$ years & $168(15 \%)$ & Yes & $57(5 \%)$ \\
\hline $35-49$ years & $464(40 \%)$ & No & $1091(95 \%)$ \\
\hline$\geq 50$ years & $516(45 \%)$ & & \\
\hline & & \multicolumn{2}{|l|}{ Organisation tenure } \\
\hline Education & & $<2$ years & $123(11 \%)$ \\
\hline Junior secondary education & $46(4 \%)$ & $2-3$ years & $87(8 \%)$ \\
\hline Senior secondary education & $64(6 \%)$ & 4-6 years & $137(12 \%)$ \\
\hline Bachelor's degree & $208(18 \%)$ & $7-10$ years & $226(20 \%)$ \\
\hline \multirow[t]{2}{*}{ Master's degree or higher } & $830(72 \%)$ & $11-15$ years & $193(17 \%)$ \\
\hline & & $\geq 16$ years & $382(33 \%)$ \\
\hline Professional sector & & Job tenure & \\
\hline Public sector & $275(24 \%)$ & $<2$ years & $224(20 \%)$ \\
\hline Finance & $111(10 \%)$ & $2-3$ years & $171(15 \%)$ \\
\hline Healthcare & $145(13 \%)$ & 4-6 years & $229(20 \%)$ \\
\hline Professional services & $149(13 \%)$ & $7-10$ years & $203(18 \%)$ \\
\hline Industry & $100(9 \%)$ & 11-15 years & $139(12 \%)$ \\
\hline Education & $90(8 \%)$ & $\geq 16$ years & $182(16 \%)$ \\
\hline Information technology & $72(6 \%)$ & & \\
\hline Energy and infrastructure & $166(15 \%)$ & & \\
\hline Wholesale and retail & $78(7 \%)$ & & \\
\hline
\end{tabular}

\subsection{Measures}

Meaningful work was measured using the Positive Meaning subscale of the Work and Meaning Inventory (Steger, Dik, \& Duffy, 2012). All items were scored on a five-point Likert scale ranging from 1 (absolutely untrue) to 5 (absolutely true). Positive meaning (PM) was assessed with four items, including "I understand how my work contributes to my life's meaning". The internal consistency of the scale was good $(\alpha=.85)$.

Perceived opportunity to craft was measured using the five-item scale developed by Van Wingerden and Niks (2017). An example is: "At work I have the opportunity to vary the type of tasks I carry out". Participants scored the items on a seven-point scale ranging from 1 (totally disagree) to 7 (totally agree). The reliability analysis showed a strong internal consistency of the scale $(\alpha=.87)$.

Job crafting was measured using 3 subscales of the Job Crafting questionnaire developed by Tims, Bakker, and Derks (2012). Of each subscale, four items were included and scored on a five-point scale ranging from 1 (never) to 5 (very often). Examples are: "I ask colleagues for advice" (increasing social job resources), "I regularly take on extra tasks even though I do not receive extra salary for them" (increasing challenging job demands), and "I try to learn new things at work" (increasing structural job resources). The internal consistencies of all three 
dimensions of the Job Crafting scale were adequate; increasing structural resources: $\alpha=.87$, increasing social job resources: $\alpha=.74$, increasing challenging job demands: $\alpha=.76$.

Work engagement was measured using the Utrecht Work Engagement Scale (UWES; Schaufeli, Bakker, \& Salanova, 2006). The instrument consists of nine items and has three subscales to assess vigor, dedication, and absorption. Examples for each subscale are "At work, I am bursting with energy" (vigor), "I am enthusiastic about my job" (dedication), and "I am immersed in my work" (absorption). Participants could respond to these items using a seven-point frequency scale ranging from 0 (never) to 6 (always). The internal consistencies of all three components of the UWES were adequate; vigor: $\alpha=.85$, dedication: $\alpha=.89$, absorption: $\alpha=.75$.

\subsection{Analysis}

The proposed model was tested with structural equation modelling (SEM) analyses using AMOS software package (Arbuckle, 2005). The chi-square, the goodness-of-fit index (GFI), and the root mean square error of approximation (RMSEA) were verified in order to determine the fit of the measurement model and alternative models to the data. The incremental fit index (IFI) and the comparative fit index (CFI) were also measured in line with Marsh, Balla, and Hau (1996). The values of GFI , IFI, CFI > .90 and RMSEA < .08 showed a reasonable fit of the model to the data (Browne \& Cudeck, 1993; Hoyle, 1995). The use of parcels in SEM results in more reliable measurement models (Little, Cunningham, Shahar, \& Widaman, 2002). We therefore conducted our SEM analysis on a partial disaggregation model (Bagozzi \& Edwards, 1998) by creating parcels of items as suggested by Hall, Snell, and Foust (1999). Parcels of items were created for the variables 'Meaningful work' and 'Perceived opportunity to craft', which were included in the model as latent factors with two indicators. 'Job crafting' and 'Work engagement' were included as latent factors with their abovementioned subscales as the indicators. We examined whether significant pathways between meaningful work and work engagement represented indirect relationships by means of bootstrapping.

\section{Results}

\subsection{Descriptive Statistics}

The means, standard deviations, reliabilities, and correlations among all study variables can be found in Table 2.

Table 2. Summary of the Descriptive Statistics for all the Main Variables, Including Means, Standard Deviations, Correlations, and Reliability Estimates (Chronbach's Alpha, Diagonal).

\begin{tabular}{llllllllllll}
\hline & $M$ & $S D$ & 1 & 2 & 3 & 4 & 5 & 6 & 7 & 8 \\
\hline 1 & Meaningful work & 3.60 & 0.72 & $(.85)$ & & & & & & & \\
2 & Perceived opportunity to craft & 4.78 & 1.17 & $.49^{* *}$ & $(.87)$ & & & & & \\
3 & Job crafting: Structural resources & 3.96 & 0.61 & $.44^{* * *}$ & $.47^{* *}$ & $(.78)$ & & & & \\
4 & Job crafting: Social resources & 2.92 & 0.75 & $.28^{* * *}$ & $.37^{* * *}$ & $.41^{* *}$ & $(.74)$ & & & \\
5 & Job crafting: Challenging demands & 3.53 & 0.75 & $.25^{* *}$ & $.36^{* *}$ & $.51^{* *}$ & $.34^{* *}$ & $(.76)$ & & \\
6 & Vigor & 4.13 & 1.08 & $.54^{* *}$ & $.52^{* * *}$ & $.45^{* *}$ & $.32^{* *}$ & $.36^{* *}$ & $(.85)$ & \\
7 & Dedication & 4.46 & 1.19 & $.69^{* *}$ & $.56^{* *}$ & $.52^{* *}$ & $.32^{* *}$ & $.36^{* *}$ & $.77^{* *}$ & $(.89)$
\end{tabular}


Note. $* p<.05, * * p<.01$.

\subsection{Hypothesis Testing}

Prior to testing the proposed model, we first set out to verify that our latent variables were accurately measured by their parcels. This was done by testing a measurement model using SPSS AMOS (Arbuckle, 2005). The results showed that the measurement model had a good fit with the data, $\chi^{2}(29)=161.332, p<.001 ; \mathrm{CFI}=.979$; TLI $=.967$; IFI $=.979$; RMSEA $=.066$ (see Table 3 for an overview of all tested models). In addition, all parcels had significant loadings on the intended factors (range $\lambda=.63-.94 ; p<.001$ ). Next, in order to assess whether or not our proposed model would fit our data, we again used SPSS AMOS to conduct a path analysis. The results showed that the proposed model had an acceptable fit with the data, $\chi^{2}(31)=221.228, p<.001 ; \mathrm{CFI}=.969$; TLI $=.955$; IFI $=.969$; RMSEA $=.076$. The coefficients of the relations are summarized in Figure 2. Meaningful work positively predicted perceived opportunities to craft $(\beta=.57, p<.001)$, which in turn positively predicted job crafting $(\beta=.67,<p .001)$, which then subsequently positively predicted work engagement $(\beta=.42, p<.001)$. In addition, there was a positive direct relationship between meaningful work and work engagement $(\beta=.56,<p .001)$.

We also tested the indirect effects of this model, using the bootstrapping analysis with bias-corrected confidence intervals (95\%) option in AMOS (MacKinnon, 2008). There was an indirect effect between meaningful work on one hand and job crafting ( $\beta=.38 ; 95 \%$ CI .32, .43; $p=.012)$ and work engagement $(\beta=.16 ; 95 \%$ CI $.13, .19 ; p=.012)$ on the other hand. There was an indirect effect between perceived opportunities to craft and work engagement as well $(\beta=.28 ; 95 \%$ CI .22, .33; $p=.010)$.

We also tested an alternative model where the relationship between meaningful work and work engagement was fully mediated by perceived opportunities to craft and job crafting. In other words, in this model the direct relationship between meaningful work and work engagement was removed. This alternative model showed a poor fit to the data, $\chi^{2}(32)=$ $541.551, p<.001 ; \mathrm{CFI}=.918 ; \mathrm{TLI}=.884 ; \mathrm{IFI}=.918, \mathrm{RMSEA}=.123$. The model fit of the alternative model was also significantly worse than the fit of the proposed model, $\Delta \chi^{2}(1)=$ $320.323, p<.001$.

Next, we tested a second alternative model where we reversed the proposed model. This meant work engagement was moved to the start of the model, which then subsequently predicted perceived opportunities to craft, job crafting, and meaningful work. This model was thus more in line with research that considers meaningful work predominantly as an outcome of job crafting instead of a predictor (e.g. Wrzesniewski, 2003). We also added the direct relationship between work engagement and meaningful work. In other words, we tested a reversed partial mediation model. This model had a sub-optimal fit, $\chi^{2}(31)=288.320, p$ $<.001 ; \mathrm{CFI}=.958 ; \mathrm{TLI}=.940 ; \mathrm{IFI}=.959 ; \mathrm{RMSEA}=.089$. Then we calculated the Akaike information criterion (AIC), since the degrees of freedom matched those of the proposed model, in order to determine which of the two models had the best quality (note: a lower value equals higher quality). Compared to the reversed partial mediation model (AIC = 


\section{1) Macrothink}

International Journal of Human Resource Studies

ISSN 2162-3058

2018, Vol. 8, No. 2

336.230), the proposed model $(\mathrm{AIC}=269.228)$ had the lowest score, and was thus deemed the superior model. We then tested a third alternative model which was similar to the second alternative model, but had the direct relationship between work engagement and meaningful work removed. In other words, we tested a reversed full mediation model. This model also had a sub-optimal fit, $\chi^{2}(32)=623.519, p<.001$; CFI $=.904$; TLI $=.866$; IFI $=.905$; RMSEA $=.132$. This fit was also significantly less optimal than the one of the proposed model, $\Delta \chi^{2}(1)$ $=402.291, p<.001$.

Lastly, we tested a direct effects model where work engagement was directly predicted by meaningful work, perceived opportunity to craft, and job crafting. This model showed a poor fit to the data, $\chi^{2}(32)=837.242, p<.001 ; \mathrm{CFI}=.870 ; \mathrm{TLI}=.817$; IFI $=.870 ;$ RMSEA $=.154$. The model fit of the direct effects model was also significantly worse than the fit of the proposed model, $\Delta \chi^{2}(1)=616.014, p<.001$. All these findings provide strong support for our proposed model.

Table 3. Fit Indices for All Models Tested in the Study, Including Chi-Square Test Results, CFI, TLI, IFI, and RMSEA.

\begin{tabular}{lccccccl}
\hline Model & $\chi^{2}$ & $d f$ & $p$ & CFI & TLI & IFI & RMSEA \\
\hline Measurement model & 161.332 & 29 & $<.001$ & .979 & .967 & .979 & .066 \\
Proposed model (partial mediation) & 221.228 & 31 & $<.001$ & .969 & .955 & .969 & .076 \\
First alternative model (full mediation) & 541.551 & 32 & $<.001$ & .918 & .884 & .918 & .123 \\
Second alternative model (reversed partial mediation) & 288.320 & 31 & $<.001$ & .958 & .940 & .959 & .089 \\
Third alternative model (reversed full mediation) & 623.519 & 32 & $<.001$ & .904 & .866 & .905 & .132 \\
Direct effects model & 837.242 & 32 & $<.001$ & .870 & .817 & .870 & .154 \\
\hline
\end{tabular}

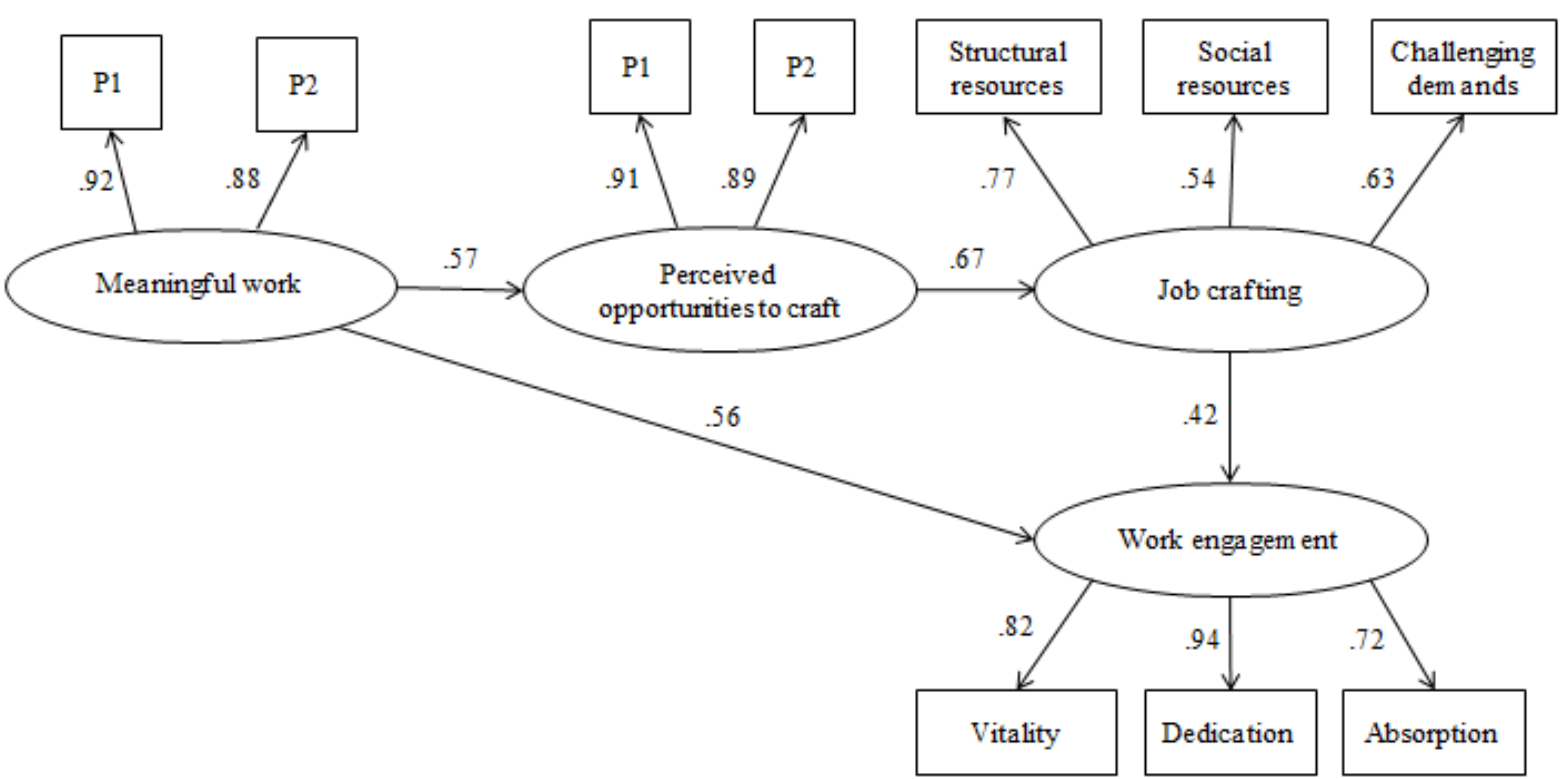

Figure 2. Final Results of the Proposed Model. Including Standardized Coefficients for all Relations

\section{Discussion}

Meaningful work is highly valued by employees (Cascio, 2003; Grant, 2007; Harpaz \& Fu, 
2002), and because of the positive relation between meaningful work and employee well-being and performance (Van Wingerden \& Van der Stoep, 2017), also by contemporary employers. Although meaningful work has been considered a key issue within organizations (Rosso et al., 2010), up till now relatively little was known about the processes through which meaningful work affects employee work engagement. The present study found support for a positive direct relation between meaningful work and employees' work engagement, and a positive indirect relation where meaningful work has a positive relation with work engagement via employees' perceived opportunities to craft their job and subsequently their job crafting behavior. All in all, this study increases our understanding of the meaningful work - work engagement relationships and further underlines the importance of experiencing meaningful work within contemporary organizations.

\subsection{Theoretical Contributions}

This study advances our understanding of the relation between meaningful work and work engagement. This study contributes to the growing body of research on meaningful work by exploring and testing how meaningful work changes employee perception and behavior at work. In this way, we advance earlier research on meaningful work and work engagement (e.g. May et al., 2004; Van Wingerden \& Van der Stoep, 2017), by further exploring the processes through which meaningful work affects work engagement. This study shows that meaningful work precedes employee perceptions, behavior and, in the end, works engagement. By comparing the fit of our model with an alternative reversed model this study further increases our understanding of the direction of the meaningful work and job crafting relationship, showing that meaningful work is more a predictor of job crafting than job crafting is a predictor of meaningful work. Where earlier research showed that meaningful work is an outcome of job crafting (Tims, Bakker, \& Derks, 2016; Wrzesniewski, 2003) the present study thus revealed that meaningful work is more of a precondition of job crafting behavior, via employees' perceived opportunities to craft. All in all, this study increases our understanding of the role that meaningful work plays within contemporary organizations.

This study further contributes to the job crafting literature by showing that employees' perceived opportunities to craft mediate the relationship between meaningful work and actual job crafting behavior. The empirical findings of this study are in line with the theoretical job crafting framework presented by Wrzesniewski and Dutton (2001), which proposes that different aspects of the work environment influence job crafting perceptions and behaviors. As far as we know, ours is the first study that provides insights into the relations between meaningful work and these job crafting perceptions and behaviors. These insights are helpful to understand which aspects of the workplace determine whether or not employees will craft their job. As job crafting is a well-known predictor of work engagement (Tims, et al., 2012; Van Wingerden, et al., 2017) this study provides new ways to stimulate work engagement via job crafting by cultivating the experience of meaningful work.

\subsection{Limitations and Suggestions for Future Research}

Although this study provides ample evidence for the hypothesized meaningful work - work engagement model, some limitations of this study need to be acknowledged. First, the results 
of this study are based on data gathered among employees who work in different industries and organizations in The Netherlands. Future research is necessary to test the meaningful work - work engagement model among employees working in other countries as well. A second limitation is the self-report nature of our data which potentially leads to self-report bias. By using self-reports we cannot evade common method bias, possibly increasing the correlations among the variables under study. Therefore, the results of this study should be interpreted with care and future research might explore additional, more objective ways to measure the variables used in this study (Podsakoff, MacKenzie, Lee, \& Podsakoff, 2013).

Another limitation of this study concerns the study design. This study has a cross-sectional and non-experimental design. Because of this design, we cannot prove causality between the constructs under study. To determine this causality, future studies should try to replicate this study using longitudinal or diary research designs. This will further answer the question of how these constructs are related over time: is meaningful work only a predictor of job crafting and work engagement, or are job crafting and work engagement also predictors of meaningful work? Such research could indicate that employees who experience meaningful work are more engaged and engaged employees experience more meaningful work, creating a reinforcing loop between meaningful work and work engagement. Future research is necessary to explore and better understand this longitudinal relation. Last, future research may focus on factors that facilitate or hinder the proposed meaningful work - work engagement relationship. For example, personal characteristics (e.g. self-efficacy) or organizational characteristics (e.g. person-organization value fit) might be crucial factors that play their part in this relationship.

\subsection{Practical Implications and Conclusion}

A practical implication of this study is that organizations should be aware of the potential impact of meaningful work on employees' perceptions, proactive behaviors and work engagement. Because of the positive (direct and indirect) relations found in this study between meaningful work and work engagement, cultivating meaningful work may provide management and HR a new way to successfully influence employee well-being at work. For example, organizations can use surveys or questionnaires to examine whether employees experience meaningful work. Based on the outcomes of these surveys, individualized reports could be made including personalized suggestions and assignments that activate employees to reflect on (their) meaningful work and to stimulate them to optimize the fit between their job and their personal preferences, motives and passions - that is job crafting (Wrzesniewski \& Dutton, 2001). The outcomes of the surveys also provide management with valuable information crucial to initiate actions that enhances the experience of meaningful work in organizations. Both managers and HR could stimulate the experience of meaningful work among employees by, for example, starting a dialogue on how the objectives of work connect to the intrinsic values and beliefs of the employees. In addition, managers can show their employees in which way everyone contributes to the team and/or organization goals. Furthermore, management plays a crucial role in the cultivation of meaningful work within organizations by clearly communicating the goals, values, and contributions of the organization. 


\section{Macrothink}

International Journal of Human Resource Studies

ISSN 2162-3058

2018, Vol. 8, No. 2

In conclusion, this study has shed more light on the meaningful work - work engagement relationship, and increased our understanding of the complex relation between these constructs. Although meaningful work positively affects work engagement, the necessity of meaningful work is often also emphasized for more ethical reasons. Michaelson and colleagues (2014), for example, consider meaningful work a human right and a moral obligation of employers. Previous research indeed revealed that meaningful work is related to employee well-being at work and in life (May et al., 2004; Van Wingerden \& Van der Stoep, 2017) highlighting the importance of the deliberate cultivation of meaningful work within organizations. This study adds to this growing body of research on the meaningful work work engagement relationship and we hope that this study will motivate other researchers and practitioners to further explore the impact of meaningful work within contemporary organizations.

\section{Funding}

This research received no specific grant from any organization or funding agency.

\section{References}

Arbuckle, J. L. (2005). Amos 6.0 User's Guide. Chicago, IL: SPSS, Inc.

Bagozzi, R. P., \& Edwards, J. R. (1998). A general approach for representing constructs in organizational research. Organizational Research Methods, 1, 45-87. https://doi.org/10.1177/109442819800100104

Baumeister, R. F., \& Vohs, K. D. (2002). The pursuit of meaningfulness in life. In C. R. Snyder \& S. J. Lopez (Eds.), Handbook of Positive Psychology (pp. 608-618). Oxford: Oxford University Press.

Berg, J. M., Dutton, J. E., \& Wrzesniewski, A. (2007). What is job crafting and why does it matter. Center for Positive Organizational Scholarship, Ross School of Business, University of Michigan.Retrieved from

http://positiveorgs.bus.umich.edu/wp-content/uploads/What-is-Job-Crafting-and-Why-Does-i t-Matter1.pdf (accessed March 3, 2016).

Browne, M. W., \& Cudeck, R. (1993). Alternative ways of assessing model fit. In K.A. Bollen and J. S. Long (Eds.), Testing structural equation models (pp. 445-455). Newbury Park, CA: Sage.

Cascio, W. F. (2003). Responsible restructuring: Seeing employees as assets, not costs. Ivey Business Journal, 68, 1-5.

Chalofsky, N. (2003). An emerging construct for meaningful work. Human Resource Development International, 1, 69-83. https://doi.org/10.1080/1367886022000016785

Demerouti, E., \& Rispens, S. (2014). Improving the image of student-recruited samples: A commentary. Journal of Occupational and Organizational Psychology, 87(1), 34-41. https://doi.org/10.1111/joop.12048 


\section{Mll Macrothink}

International Journal of Human Resource Studies ISSN 2162-3058 2018, Vol. 8, No. 2

Grant, A. M. (2007). Relational job design and the motivation to make a prosocial difference. Academy of Management Review, 32, 393-417. https://doi.org/10.5465/AMR.2007.24351328

Hackman, J. R., \& Oldham, G. R. (1980). Work redesign. Reading, MA: Addison- Wesley.

Hall, R. J., Snell A. F., \& Foust, M. (1999). Item parceling strategies in SEM: Investigating the subtle effects of unmodeled secondary constructs. Organizational Research Methods, 2, 233-256. https://doi.org/10.1177/109442819923002

Harpaz, I., \& Fu, X. (2002). The structure and the meaning of work: A relative stability amidst change. Human Relations, 55, 639-668. https://doi.org/10.1177/0018726702556002

Hoyle, R. H. (1995). Structural equation modeling: Concepts, issues, and applications. Thousand Oaks, CA: SAGE.

LePine, J. A., \& Van Dyne, L. (1998). Predicting voice behavior in work groups. Journal of Applied Psychology, 83, 853-868. https://doi.org/10.1037/0021-9010.83.6.853

Linley, P. A., \& Harrington, S. (2006). Strengths coaching: A potential-guided approach to coaching psychology. International Coaching Psychology Review, 1, 37-46.

Little, T. D., Cunningham, W. A., Shahar, G., \& Widaman, K. F. (2002). To parcel or not to parcel: Exploring the question, weighing the merits. Structural Equation Modeling, 9, 151-173. https://doi.org/10.1207/S15328007SEM0902_1

MacKinnon, D. P. (2008). Introduction to statistical mediation analysis. London: Routledge.

Marsh, H. W., Balla, J. R., \& Hau, K. T. (1996). An evaluation of Incremental Fit Indices: A clarification of mathematical and empirical properties. In G. A. Marcoulides \& R. E.

May, D. R., Gilson, R. L., \& Harter, L. M. (2004). The psychological conditions of meaningfulness, safety and availability and the engagement of the human spirit at work. Journal of Occupational and Organizational Psychology, 77, 11-37. https://doi.org/10.1348/096317904322915892

Michaelson, C., Pratt, M. G., Grant, A. M., \& Dunn, C. P. (2014). Meaningful work: Connecting business ethics and organization studies. Journal of Business Ethics, 121, 77-90. https://doi.org/10.1007/s10551-013-1675-5

Nair, N., \& Vohra, N. (2009). Developing a new measure of work alienation. Journal of Workplace Rights, 14, 293-309. https://doi.org/10.2190/WR.14.3.c

Neck, C. P., \& Milliman, J. F. (1994). Thought self-leadership: Finding spiritual fulfilment in organizational life. Journal of Managerial Psychology, 9(6), 9-16. https://doi.org/10.1108/02683949410070151

Podsakoff, P. M., MacKenzie, S. B., Lee, J., \& Podsakoff, N. P. (2013). Common method bias in behavioral research: A critical review of literature and recommended remedies. Journal of Applied Psychology, 88, 879-903. https://doi.org/10.1037/0021-9010.88.5.879

Pratt, M. G., \& Ashford, B. E. (2003). Fostering meaningfulness in working and at work. In K. 
Cameron, J. E. Dutton, \& R. E. Quinn (Eds), Positive organizational scholarship: Foundations of a new discipline (pp. 308-327). San Francisco: Berrett-Koehler.

Rosso, B. D., Dekas, K. H., \& Wrzesniewski, A. (2010). On the meaning of work: A theoretical integration and review. Research in Organizational Behavior, 30, 91-127. https://doi.org/10.1016/j.riob.2010.09.001

Schaufeli, W. B., \& Bakker, A. B. (2004). Job demands, job resources and their relationship with burnout and engagement: A multi sample study. Journal of Organizational Behavior, 25, 293-315. https://doi.org/10.1002/job.248

Schaufeli, W. B., Bakker, A. B., \& Salanova, M. (2006). The measurement of work engagement with a short questionnaire: A cross-national study. Educational and Psychological Measurement, 66, 701-716. https://doi.org/10.1177/0013164405282471

Schumacker (Eds.), Advanced structural equation modeling: Issues and techniques (pp. 315-353). Mahwah, NJ: Lawrence Erlbaum Associates.

Seibert, S. E., Wang, G., \& Courtright, S. H. (2011). Antecedents and consequences of psychological and team empowerment in organizations: A meta-analytic review. Journal of Applied Psychology, 96, 981-1003. https://doi.org/10.1037/a0022676

Shantz, A., Alfes, K., \& Truss, C. (2014). Alienation from Work: Marxist Ideologies and $21^{\text {st }}$ Century Practice. International Journal of Human Resource Management, 25, 2529-2550. https://doi.org/10.1080/09585192.2012.667431

Steger, M. F., Dik, B. J., \& Duffy, R. D. (2012). Measuring meaningful work: The work and meaning inventory (WAMI). Journal of Career Assessment, 20, 322-337. https://doi.org/10.1177/1069072711436160

Thomas, K. W., \& Velthouse, B. E. (1990). Cognitive elements of empowerment: An "interpretive" model of intrinsic task motivation. Academy of Management Review, 15, 666-681.

Tims, M., Bakker, A. B., \& Derks, D. (2012). Development and validation of the job crafting scale. Journal of Vocational Behavior, 80, 173-186. https://doi.org/10.1016/j.jvb.2011.05.009

Tims, M., Bakker, A. B., \& Derks, D. (2016). Job crafting and its relationships with person-job fit and meaningfulness: A three-wave study. Journal of Vocational Behavior, 92, 44-53. https://doi.org/10.1016/j.jvb.2015.11.007

Van Wingerden, J., \& Niks, I. (2017). Construction and validation of the Perceived $\begin{array}{llllll}\text { Opportunity to Craft Scale. Frontiers in Psychology, 8, } 573 . & \text {. }\end{array}$ https://doi.org/10.3389/fpsyg.2017.00573

Van Wingerden, J., \& Poell, R. F. (2017). Employees' perceived opportunities to craft and in role performance: The mediating role of job crafting and work engagement. Frontiers in Psychology, 8, 1876. https://doi.org/10.3389/fpsyg.2017.01876

Van Wingerden, J., \& Poell, R. F. (in press). Employees' job characteristics and job crafting 


\section{Macrothink}

International Journal of Human Resource Studies

ISSN 2162-3058 2018, Vol. 8, No. 2

behavior: The mediating role of perceived opportunities to craft. Fronties in Psychology, in press.

Van Wingerden, J., \& Van der Stoep, J. J. (2017). The role of meaningful work in employees' work related and general well-being. International Journal of Human Resource Studies, 7, 23-37. https://doi.org/10.5296/ijhrs.v7i4.11611

Van Wingerden, J., \& Van der Stoep, J. J. (in press). The motivational potential of meaningful work: Relationships with strengths use, work engagement, and performance. In press.

Van Wingerden, J., Bakker, A. B., \& Derks, D. (2017). Fostering employee well-being via a job crafting intervention. Journal of Vocational Behavior, 100, 164-174. https://doi.org/10.1016/j.jvb.2017.03.008

Van Wingerden, J., Derks, D., Bakker, A. B., \& Dorenbosch, L. (2013). Job crafting in het speciaal onderwijs: een kwalitatieve analyse [Job crafting in special education: A qualitative analysis]. Gedrag \& Organisatie, 26, 85-103.

Wrzesniewski, A. (2003). Finding positive meaning in work. In K. S. Cameron, J. E. Dutton,\& R. E. Quinn (Eds.), Positive organizational scholarship: Foundations of a new discipline (pp. 298-308). San Francisco, CA: Berrett-Koehler.

Wrzesniewski, A., \& Dutton, J. E. (2001). Crafting a job: Revisioning employees as active crafters of their work. Academy of Management Review, 26, 179-201.

Wrzesniewski, A., McCauley, C., Rozin, P., \& Schwartz, B. (1997). Jobs, careers, and callings: People's relations to their work. Journal of Research in Personality, 31, 21-33. https://doi.org/10.1006/jrpe.1997.2162

\section{Copyright Disclaimer}

Copyright for this article is retained by the author(s), with first publication rights granted to the journal.

This is an open-access article distributed under the terms and conditions of the Creative Commons Attribution license (http://creativecommons.org/licenses/by/4.0/). 